\title{
Discussion on the Meaning of Setting up Bodybuilding Course in Ordinary Colleges
}

\author{
Guozheng Zhu \\ Henan Institute of science and technology \\ Xinxiang, China 453003
}

\begin{abstract}
Bodybuilding course is a kind of physical education course in ordinary colleges which is based on the study of medical, aesthetics, biology, etc, and it helps students master bodybuilding methods effectively and educates themselves and others to engage in amateur bodybuilding. Bodybuilding is gradually accepted by students and develops quite well in colleges because its special fitness function that are pertinence, high efficiency, reasonable load intensity, selectivity in quantity, the dual nature of healthy body and mind.
\end{abstract}

Keywords-fitness class; physical education in college; bodybuilding

\section{INTRODUCTION}

With the rapid development of economy in China, people's living standard has been improved constantly. And the changes both in labor methods and dietary structure have caused many negative effects to people's health, which brings about the disease of modern civilization. In order to improving physical quality and enhancing health, the national fitness upsurge has been formed in China.

Moreover, with the promulgation of the Chinese sports law and practical implementation of the national fitness program, the basic framework of the national fitness system with Chinese characteristics has been formed. For all kinds of sports programs, what people are interested in and what will they take part in have changed a great deal when they are in bodybuilding activities in this new stage. Having a healthy body and toned figure is a fashion for modern to pursue. Body building, which aims at building stronger and healthier body, has gained more and more recognition by the young and middle-aged. Bodybuilding course is one kind of physical education course in ordinary colleges and universities, which are based on learning Human Anatomy, Sports Physiology, Sports Medicine, Nutrition and Sports Aesthetics Principle to master the methods of developing muscles, enhancing the muscle strength, improving body form and posture effectively and educates oneself and others to engage in amateur bodybuilding exercise and advocates healthy new idea and form a good habit of lifelong physical exercise. Bodybuilding is gradually accepted by students and develops quite well in colleges because its special fitness function that are pertinence, high efficiency, reasonable load intensity, selectivity in quantity, the dual nature of healthy body and mind.

\section{RELATED DEFINITION OF BODYBUILDING}

The nature of a course can be embodied by its definition and contents, which is the basis of one course's existence as well as the condition of its development. Many scholars have summarized bodybuilding exercise from different aspects, and the definition is as follows: Bodybuilding is a kind of sports item, which is using special actions and methods to exercise by bare hands and all kinds of equipment to develop muscle, increase strength, improve the form and edify sentiment. There are various kinds of bare-handed exercise such as different kinds of aerobics, rhythmic exercise, bodybuilding exercise, and all kinds of resistance movements. It also can exercise with various equipments. Such as: barbell, dumbbell, kettlebell for weight-lifting; single bar and parallel bars for gymnastics; spring pressure machine, pulley wheel ,elastic band and many other kinds of special comprehensive strength trainers. Body building is a physical education course used for transforming human's body. It is not only conducive to physics, psychology and aesthetics in microcosmic aspect but also benefit the nation, people and family in macroscopic aspects in terms of its function. The summations of definition for bodybuilding are pretty clear and specific.

\section{BODYBUILDING AND STUDY ON THE EFFECT OF BODYBUILDING COURSE IN COLLEGES}

The efficiency and pertinence as well as the function of improving the body and mind and contributing to social adaptation of bodybuilding have been well demonstrated. Pang Yubo and Dong Xinya used the method of experiment to demonstrate the effect of bodybuilding exercise and arrived at a conclusion that bodybuilding course in colleges and universities can meet students' specific conditions and requirements and give full play to the students' enthusiasm, initiative and creativity, so it is one of the effective forms to promote and implement "health first" guiding ideology. It requires enough attention to key techniques, action rhythm, breathing method, mental guidance and training rules, intermittent mode, rest and nutrition during the teaching course. While Wang Chuanmao put forward specific fitness plans on the basis of different effects of bodybuilding ,according to the investigation on different purpose and demand of bodybuilding exercises of different crowds.

In August 2003, National Department of Education issued the new Guiding Outline of Physical Education Curriculum in 
Colleges and Universities. It stipulated that body building is the elective course of Physical Education in all National Ordinary Colleges and University. Body building has a good development in many colleges. Xu Qinhua had proved the feasibility of establishing Bodybuilding classes in colleges with the examples of test that for ten years establishment of bodybuilding team and classes in the school. Liang Hongtao had expounded the necessity of setting up bodybuilding class by discussing its concept, peculiarities and functions.

\section{THE IMPORTANT SIGNIFICANCE OF SETTING UP THE BODYBUILDING COURSE IN COLLEGES}

Bodybuilding is a kind of sports item, which is using special actions and methods to exercise by bare hands and all kinds of equipment to develop muscle, increase strength, improve the form and edify sentiment.

"Bodybuilding is a physical education course used for transforming human's body. In all kinds of sports programs, which is the only one that has been created by people who have been inspired by the statues of human movement". It is not only conducive to physics, psychology and aesthetics in microcosmic aspect but also benefit the nation, people and family in macroscopic aspects in terms of its function.

With the continuous development and usage of the new knowledge and technology, new methods and equipment, it fully shows the vitality of bodybuilding and its huge potential market. As a sports program with strong pertinence and scientific nature, bodybuilding is bound to be the main stream of people's sports and fitness, and the main content of people's life style because of its dual nature of healthy body and mind and unique higher efficiency.

In recent years, body building has been listed into the formal sports event in the world games and national sports meeting. In 2002 and 2006, Asian Games has ranked body building as the official match. In Nov, 2005, China succeeded in hosting the 59th world bodybuilding championship in Shanghai. On the count of this better situation, the study on the current situation of opening the bodybuilding course in ordinary college promotes the development of bodybuilding. Meanwhile, strengthening the study on bodybuilding course in colleges and universities has the important theory value and practical significance for school physical education and mass sports.

\section{A. Provided an Opportunity for the Development of Bodybuilding by the Fusion of East and West Culture}

Chinese culture is gradually weak over the last hundred years, and then it will be the only choice that Chinese people learn or copy from the West. The introduction of western sports is the most representative. Western sports have been pursued by Chinese people for its unique social cultural phenomenon and cultural carrier. But wholesale westernization is not developed well in China. Along with the arriving of globalization, cultural exchange between East and West is increasingly widespread, turning from single learning, binary confrontation and cultural conflict to multiple communication and cultural interaction.
Bodybuilding birthed with profound Western culture, and it is popular after introducing into China. The development of bodybuilding has its necessity of existence. Under the background of the East and West culture fusion, multiple Communication and culture interaction, it would be significant opportunities and challenges for the development of bodybuilding if the traditional Chinese culture and Western culture integrate into bodybuilding and it is accepted by the vast Chinese people.

\section{B. Created Conditions for the Development of Bodybuilding by the Development of Modern Society}

Now, China is in the market regulation of the modern economic society, with the advance of the market regulation, the social elements have changed a great deal, and this change provides the condition for the development of bodybuilding.

1) The decline of primary community and the development of secondary group: With the acceleration of social mobility, the development of mass media, the change of values, and the reduction of family size, the communication between people tend to be transient, indirect and utilitarian. The primary community, which is characterized by emotional color, is not only decreasing in quantity, but also declining in quality. Now, people have more relations than the past, and through various secondary relations to seek their own development. The generation of various service classes of social organizations, has made "at home depend parents, go out on friends" this traditional concept greatly changed. "The sports facilities are simple, safe and easy to carry out", which provides the possibility of participation of all people, especially in terms of economic efficiency, and shows the advantages of its universality ". The establishment of various types of high and low class fitness clubs fully demonstrated this point. The development of bodybuilding has solved the bodybuilding problem the changing society brings about, but also provides a platform for the development of bodybuilding.

2) The accelerated process of urbanization in China: Now, in China, urbanization has reached over 39\%, the city population is close to or even more than $350,000,0000$, and the scale of city will accelerate development in this important historical period - building a moderately prosperous society in all respects. "City is the carrier of modern civilization, the important function of urbanization is to improve the overall quality of the Chinese people by the influence of modern civilization. The characteristics of city are huge population with high density, complex social division of labor, and increased degree of specialization and modern life style, which provides favorable conditions for the development of bodybuilding and the commercial fitness clubs.

3) Meet the New Fitness Needs of People in Present Times through Body Building: Nowadays, people's view of health is changing with the progress of society and the development of sports. People are no longer satisfied with the simple health, but on the basis of health to pursue of beautiful posture and pretty figure, to reach the fitness purpose on the 
basis of bodybuilding. The physical and mental development accords with the general goal of fitness body health, mental health, and graceful figure. Its special micro effects of bodybuilding are matched with the needs of people's health in modern times. The characteristics of sports which are the continuity of movement, the specific purpose, the amount of movement, the class of the crowd, and the simplicity of technology just meet the different needs of people on different age and gentle.

\section{Theoretical Support for the Development of Bodybuilding Course Provided by Sports Reform in the School}

1) Transformation of educational thought: Since reform and opening up, in short, the evolution of school sports thought is along the main clue from the logic starting point by the single biological discipline to the development of multiple disciplines, such as biological, psychological, social, pure biological sports view to 2-D sports view on body, mental, and 3-D view on biological, psychological, social, and the progress of the humanities sports view, and it has formed the basic conception the current people agreed, which guides the direction of the reform of school physical education: adhere to "health first" guiding ideology, promote students' healthy growth; stimulate their interest in sport, and cultivate students' lifelong sports consciousness; center on students' development, pay attention to student's dominant role; focus on the individual differences in different needs to ensure that every student benefits. It is exactly the same effect with those of bodybuilding course' and promotes the development of bodybuilding.

2) Establish the teaching objectives: At present, the sports teaching objectives include: enhance physical fitness, master and apply the basic knowledge of sports and health and the sports skills; cultivate sports interest and hobbies, form the habit of doing exercise frequently; have a good psychological quality, show the interpersonal ability and cooperation spirit; improve the sense of responsibility for personal health and community health, form a healthy lifestyle; develop the sports spirit, form a positive, optimistic, cheerful attitude to life". With various purposes: developing muscle, increasing strength, improving the form and edify sentiment, body building will play an irreplaceable role to achieve the physical education teaching objectives, and bodybuilding course will also get a better development on this platform.

3) The evolution of course content: According to the characteristics of sports, the 4-D healthy view, and the trend of the development of the sports curriculum at home and abroad, new course content has changed the framework of the course content which was divided according to sports items in the past. Now, the sports course content is divided into sports participation, sports skills, physical health, mental health and social adaptation five learning areas, and with the characteristics of keeping fit, scientific nature, interest, effectiveness and characteristics of simplicity to meet the new requirements of modern people. Bodybuilding course with the love of body building, advocate a new healthy concept and form the habit of lifelong physical exercise is consistent with the new course content. Bodybuilding course will become an important part of the new course content.

4) The development of teaching organization: " The form of teaching organization about the combination of in class and out-of class and the club type meet the modern times' requirements and students' needs." The development of bodybuilding must be based on these two forms, which make the bodybuilding course in colleges extends to outside class effectively. This promotes the development of body building and the implementation of the national fitness. Meanwhile, the emergence of many commercial fitness clubs provides conditions for the formation of lifelong sports.

\section{Bodybuilding Sports Being Helpful for the Implementation of the National Fitness Program}

National bodybuilding program is a magnificent cause that it improves the quality of the whole nation and revitalizes the Chinese nation; it is a cross-century systems engineering matches the socialist modernization; it is a great strategic measure in sports revolution. This year is 12th anniversary of the implementation of the Outline of the Whole People Body Building Project. During these twelve years, it has achieved gratifying results. In national fitness items, bodybuilding, with its characteristics: "build up body strength, edify sentiment, and beautify the body and mind", "simple equipment, easy to carry out and "strong adaptability, all appropriate", body building has provided the possibility of everyone involved and shows its advantage of universality. Under the domination of direct interest and indirect interest, bodybuilding gradually becomes one of the first choices about people's health activities. The bodybuilding effect can be seen in every sports industry: the sports service system is established under the government's macroeconomic regulation and chosen independently by the sports service department. Its main form is fitness clubs which focus on body building. The establishment of the public bodybuilding facilities is according to the efficient bodybuilding equipment. At the same time, bodybuilding is quite different with the features of the Chinese traditional martial arts and regimens, and it becomes a beneficial supplement of them constantly.

\section{E. Establishing Bodybuilding Course in College Playing A Positive Role in Carrying out the Quality Education for College Students Under This New Situation}

"College students is the elite group of young population, it has been considered as one of the healthy groups all the time, because everyone candidate for College Entrance Examination is qualified on health form. However, the reality has a distance with our imagination, and the physical quality of college students, even health condition, is not satisfactory". With the multiple effects of strong pertinence, high efficiency and healthy body and mind, bodybuilding plays a positive role in carrying out college students' physical quality, psychological quality and the ability of adapting the society. Bodybuilding meets the fitness needs of various groups. Meanwhile, it comes to be a choice and accepted by college students. 


\section{REFERENCES}

[1] Shu Peihua. Fit and Happy; Bodybuilding Handbook for Man[M]. Beijing: Beijing Sport University Press, 2003:36-38.

[2] Tang Yumei, Zhao Zhimei. Status Analysis on the Body Building of Guangxi College Students[J].Journal of Xinyang Normal University, 2001, 21(6):40-42.

[3] Group Department of General Administration of Sports of China. Special Materials of Training on Social Sports Instructor: Body Building [M]. Higher Education Press, 2005:25-30.

[4] Yang Xiaojie, Zhou Zihua. New Aerobics Course[M]. Beijing: Hehai University Press, 2003:44-48.

[5] Sun Hanchao. Research on Chinese Residents' Consumption Behavior on Sports[M]. Beijing: People's Sports Press, 2001:235-238. 